\title{
Structure Proposal for a New Pyoverdin from Pseudomonas sp. PS 6.10
}

\author{
Herbert Budzikiewicz ${ }^{\mathrm{a}, *}$, Mathias Schäfer ${ }^{\mathrm{a}}$, Diana Uría Fernández ${ }^{\mathrm{a}, \mathrm{b}}$, \\ and Jean-Marie Meyer ${ }^{\mathrm{c}}$ \\ a Institut für Organische Chemie der Universität zu Köln, Greinstr. 4, D-50939 Köln, \\ Germany. Fax +49-221-470-5057. E-mail: aco88@uni-koeln.de \\ b Present address: Waters MS Technology Centre, Manchester, UK \\ c Laboratoire de Microbiologie et de Génétique, UPRES-A 7010 du CNRS, Université Louis \\ Pasteur, 28 rue Goethe, F-67000 Strasbourg, France \\ * Author for correspondence and reprint requests \\ Z. Naturforsch. 61c, 815-820 (2006); received August 22, 2006
}

From Pseudomonas sp. PS 6.10, when grown in a casamino acid medium, a pyoverdin was isolated whose primary structure could be deduced from its mass spectrometric fragmentation pattern and amino acid analysis. It belongs to the smallest representatives of this group of siderophores comprising only six amino acids in its peptide chain. When grown in a succinate minimal medium the corresponding ferribactin considered to be the biogenetic precursor of the pyoverdin was obtained as the major component.

Key words: Pseudomonas, Pyoverdin, Siderophore

\section{Introduction}

Pseudomonas sp. PS 6.10 is a member of the fluorescent species in the rRNA homology group I of the family Pseudomonadaceae which produces siderophores ("pyoverdins") with high $\mathrm{Fe}^{3+}$ complexing constants. The strain was isolated from the cultivated mushroom Agaricus bisporus as a member of the "Pseudomonas reactans" group since it was non-pathogenic and developed a positive white line test against Pseudomonas tolaasii (Munsch et al., 2000). Furthermore, siderotyping analysis of the strain showed that its pyoverdin-isoelectrofocussing pattern was original and that the pyoverdin was highly strain-specific in its iron transport capacity.

Today about 50 complete or fairly complete pyoverdin structures have been elucidated (Budzikiewicz, 2004; Fuchs et al., 2001), and from preliminary siderotyping studies it appears that many more are to be expected. Pyoverdins consist of three distinct structural parts, viz. a dihydroxyquinoline chromophore responsible for their fluorescence, a peptide chain comprising 6 to 12 amino acids bound to the chromophore carboxy group,

Abbreviations: Common amino acids, 3-letter code; Dab, 2,4-diaminobutanoic acid; AcOHOrn, $N^{4}$-acetyl- $N^{4}$-hydroxy Orn; OHAsp, threo- $\beta$-hydroxy Asp; MS, mass spectrometry; ESI, electrospray ionization; CA, collision activation. and a small dicarboxylic acid (or its monoamide) connected amidically to its $\mathrm{NH}_{2}$ group (cf. 1). The peptide chain has a twofold function. It provides two of the ligand sites for $\mathrm{Fe}^{3+}$, and it is responsible for the recognition of the ferri-pyoverdins by specific receptors located at the surface of the producing cell (Meyer et al., 2002). The variability of the peptide chain is closely connected with the second function: It safeguards that a given ferri-pyoverdin is available only to the producing strain because of the usually highly specific interaction between the ferri-pyoverdin and its receptor outer membrane protein (Hohnadel and Meyer, 1988).

In the bacterial culture medium occasionally together with pyoverdins compounds are encountered which are considered to be their biogenetic precursors. They have the same peptide chain as the corresponding pyoverdins, but differ in the $\mathrm{N}$-terminal part. Thus in ferribactins the pyoverdin chromophore is replaced by a condensation product of D-Tyr and L-2,4-diaminobutanoic acid (Böckmann et al., 1997; Hohlneicher et al., 1992, 2001). The strain presently studied, Pseudomonas sp. PS 6.10, when grown in a casamino acid medium, produced large amounts of pyoverdin, but in succinate minimal medium the corresponding ferribactin was produced as the major component.

Over the years much knowledge has been accumulated on the mass spectrometric fragmentation behavior of pyoverdins after electrospray ioniza- 
tion (ESI) and collisional activation (CA) (Budzikiewicz, 2004; Fuchs and Budzikiewicz, 2001a) which in many cases allows the determination of the amino acid sequence of the peptide chain, even from crude bacterial culture extracts without previous isolation of the siderophores. We wish to demonstrate this for a pyoverdin and the corresponding ferribactin obtained from the Pseudomonas sp. PS 6.10 strain.

\section{Materials and Methods}

Mass spectrometry was done using a FinniganMAT 900 ST with an ESI source, solvent $\mathrm{CH}_{3} \mathrm{OH} /$ $\mathrm{H}_{2} \mathrm{O}$ 1:1. Mass selected fragmentation by CA was conducted either in the quadrupole region in front of or in the ion trap. GC-MS analysis of the trifluoroacetyl isopropyl (TAP) derivatives of the amino acids obtained by hydrolysis was performed with an Agilent Technologies GC 6890 apparatus. Chiral amino acid analysis of the TAP derivatives was effected on a Chirasil-L-Val column (Chrompack, Frankfurt) using a Varian 3400CX GC apparatus.

The bacterial strain was grown either in a casamino acid or in a succinate minimal medium (Meyer et al., 1997). For the work-up of the culture after addition of ferric citrate and the isolation of the ferri-pyoverdins by chromatography on XAD4 resin see Georgias et al. (1999). Siderotyping controls including isoelectrophoresis analysis of the pyoverdins and pyoverdin-mediated iron uptake studies were done as described previously (Munsch et al., 2000).

\section{Results}

\section{Pyoverdins}

After total hydrolysis and TAP derivatization by GC/MS analysis and GC analysis using a chiral column (Dallakian et al., 1999) the presence of DAla, OHAsp, L-Dab, L-Lys, L-Orn and/or OHOrn was established.

The molecular mass of the main component was determined by ESI-MS as 1090 u. As will be shown below it corresponds to a species with a succinamide side chain (Fig. 1, 1a). For structure elucidation the precursor ions $[\mathrm{M}+\mathrm{H}]^{+}$or $[\mathrm{M}+2 \mathrm{H}]^{2+}$ of $1 \mathrm{a}$ were excited by CA both in the quadrupole region and in the ion trap of the mass spectrometer. In the quadrupole several collisions may occur and ions resulting from consecutive fragmentation processes will be observed. In the ion trap a single ion species is selected and only single-step fragmentation processes are possible, but the relatively long lived ions in the trap may

Table I. Amino acid sequence characteristic fragment ions found in the MS-CA spectra of $[\mathrm{M}+\mathrm{H}]^{+}$and/or of $[\mathrm{M}+2 \mathrm{H}]^{2+}$ of $\mathbf{1 a}($ see text).

\begin{tabular}{llcccc}
\hline$n$ & Amino acid & A & B & $\mathrm{Y}^{\prime \prime}$ & $n$ \\
\hline 1 & Ala & 400 & 428 & & 6 \\
2 & Orn & & 542 & & 5 \\
3 & OHAsp & & 673 & 550 & 4 \\
4 & Dab & & 773 & 419 & 3 \\
5 & AcOHOrn & & 945 & 319 & 2 \\
6 & Lys & & & 147 & 1 \\
\hline
\end{tabular}

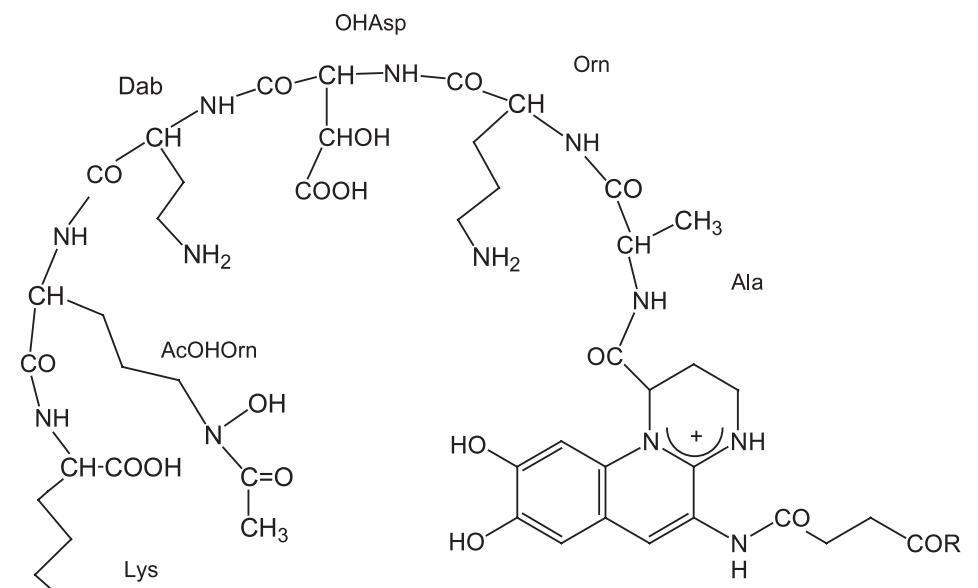




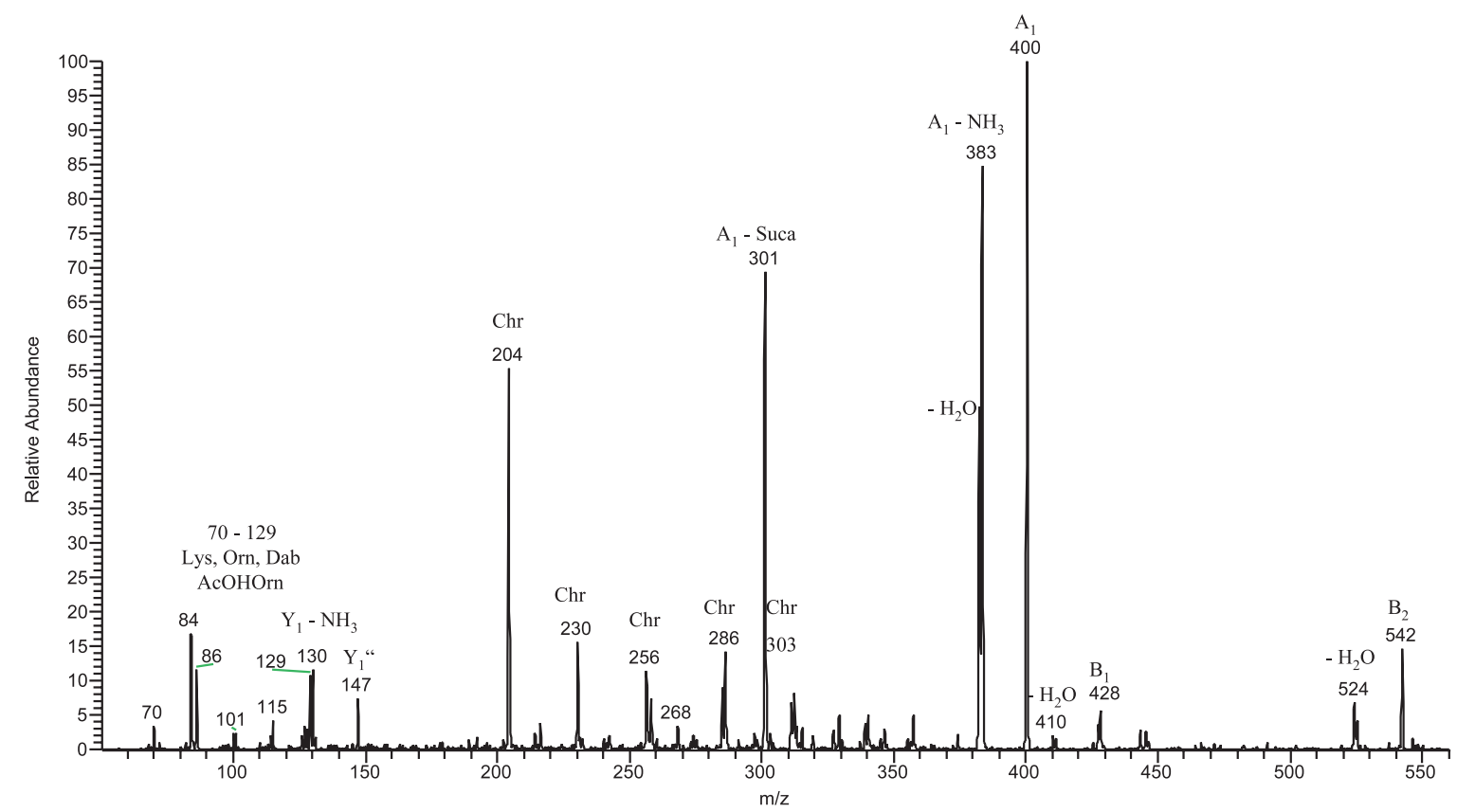

Fig. 2. Quadrupole ion CA mass spectrum (lower part) of $[\mathrm{M}+2 \mathrm{H}]^{2+}$ of 1a. Marked with Chr are the fragments formed by retro-Diels-Alder decomposition of the chromophore $(\mathrm{m} / \mathrm{z}, 303)$ and its further cleavage products; $\mathrm{m} / \mathrm{z}$ 70-129 comprise the fragments characteristic for amino acids (see text).

partially undergo rearrangement processes. CA of $[\mathrm{M}+\mathrm{H}]^{+}$mainly yields fragments containing the protonated chromophore, while in the CA spectra of $[\mathrm{M}+2 \mathrm{H}]^{2+}$ also ions comprising parts of the $C$ terminus of the peptide chain (Y-ions). [The $N$-terminal fragments obtained by cleavage before, in or after peptide bond - $\mathrm{CHR}-\mathrm{CO}-\mathrm{NH}-\mathrm{CHR}^{\prime}-$ are designated by $\mathrm{A}, \mathrm{B}$, and $\mathrm{C}$, the $C$-terminal ones by $\mathrm{X}, \mathrm{Y}$, and $\mathrm{Z}$. The number of transferred hydrogen atoms is indicated by hyphens. Thus, $-\mathrm{CHRCO}^{+}$is a $\mathrm{B}$ ion, $\mathrm{H}_{3} \mathrm{~N}^{+}-\mathrm{CHR}^{\prime}-$ an $\mathrm{Y}^{\prime \prime}$ ion (Roepstorff and Fohlman, 1984).] are observed, since the second proton can induce fragmentation anywhere in the chain (Budzikiewicz, 2004; Fuchs and Budzikiewicz, 2001a).

Both in the quadrupole and the ion trap CA spectra of $[\mathrm{M}+\mathrm{H}]^{+}\left(\mathrm{m} / \mathrm{z}\right.$ 1091) loss of 1 to $4 \mathrm{H}_{2} \mathrm{O}$ molecules is observed. Cleavage of the various peptide bonds yields $A_{1}$ and the complete series of $\mathrm{B}$ ions (see Table I). All these ions show loss of $\mathrm{H}_{2} \mathrm{O}, \mathrm{A}_{1}$ in addition loss of $\mathrm{NH}_{3}$ and of the entire succinamide residue with back transfer of one $\mathrm{H}$ atom $(m / z \quad 301) . \quad\left[\mathrm{B}_{3}-\mathrm{H}_{2} \mathrm{O}\right]^{+}(\mathrm{m} / \mathrm{z} \quad 655)$ loses HOOC-CHO from OHAsp by a McLafferty rearrangement (transfer of $\mathrm{H}$ to the peptide car- bonyl group) $(\mathrm{m} / z, 581) . \mathbf{B}_{5}(\mathrm{~m} / z, 945)$ is accompanied by $\left[\mathrm{B}_{5}+\mathrm{H}_{2} \mathrm{O}\right]^{+}(\mathrm{m} / z$ 963) formed by transfer of the $C$-terminal hydroxy group (Fuchs and Budzikiewicz, 2001b).

In the quadrupole CA spectrum (Fig. 2) of $[\mathrm{M}+2 \mathrm{H}]^{2+}(\mathrm{m} / \mathrm{z} 546)$ the retro-Diels-Alder fragmentation of the chromophore can be observed. Loss of C-2 and C- 1 of the protonated chromophore together with the peptide chain leads to $m / z$ 303 of low abundance, because this ion decomposes further by the loss of $\mathrm{NH}_{3}$ and subsequently $\mathrm{CH}_{2} \mathrm{O}(\mathrm{m} / \mathrm{z} 286$ and 256$)$, of $\left[\mathrm{CH}_{2}-\mathrm{CH}_{2}-\right.$ $\left.\mathrm{CONH}_{2}+\mathrm{H}\right](\mathrm{m} / z$ 230) and of the entire side chain with back-transfer of a $\mathrm{H}$ atom $(\mathrm{m} / \mathrm{z}, 204)$. This fragmentation is characteristic for a pyoverdin chromophore (in contrast to isopyoverdins) (Fuchs and Budzikiewicz, 2001a). Ions at $\mathrm{m} / \mathrm{z}$ 129/ $84,115 / 70$ and 101 (the expected $\mathrm{m} / \mathrm{z} 56$ is beyond the recording range of the instrument) are in agreement with the presence of Lys, Orn and Dab $\left[\mathrm{H}_{2} \mathrm{~N}-\left(\mathrm{CH}_{2}\right)_{n}-\mathrm{CHNH}_{2}-\mathrm{CO}^{+}\right.$and $\mathrm{H}_{2} \mathrm{~N}-\left(\mathrm{CH}_{2}\right)_{n-1}$ $-\mathrm{CH}=\mathrm{CH}^{+}$], respectively, those at $\mathrm{m} / z, 114$ and 86 with an $N^{4}$-acyl- $N^{4}$-hydroxy-ornithine residue $\left(\mathrm{NHOH}-\mathrm{CH}_{2}-\mathrm{CH}_{2}-\mathrm{CH}=\mathrm{CH}-\mathrm{CO}^{+}\right.$and subsequent loss of $\mathrm{CO}$ ). 
Most pronounced is the signal at $m / z, 400$ representing the $A_{1}$ ion. Abundant $A_{1}$ and weak $B_{1}$ ions are typically observed with a small neutral amino acid bound to the chromophore, in the present case Ala. $\mathrm{A}_{1}$ can lose $\mathrm{NH}_{3}(\mathrm{~m} / \mathrm{z}, 383), \mathrm{H}_{2} \mathrm{O}(\mathrm{m} / \mathrm{z}$ $382)$, and the entire side chain $(\mathrm{m} / z, 301) . \mathbf{B}_{2}$ can be found at $m / z$ 542. The mass difference corresponds to Orn.

In the ion trap CA spectrum of $[\mathrm{M}+2 \mathrm{H}]^{2+}$ again the whole series of $\mathrm{B}$ ions can be seen as well as the loss of $\mathrm{H}_{2} \mathrm{O}$, HOOC-CHO from $\mathrm{m} / z, 655$ and formation of $\left[\mathrm{B}_{5}+\mathrm{H}_{2} \mathrm{O}\right]^{+}$as discussed above, but in addition the $\mathrm{Y}^{\prime \prime}$ ions up to $\mathrm{Y}_{4}{ }^{\prime \prime}(\mathrm{m} / \mathrm{z} 550)$ are present (see Table I).

These results allow to propose the structure $\mathbf{1}$ (Fig. 1) for the pyoverdin of Pseudomonas sp. PS 6.10. The conclusions derived from the mass spectrometric fragmentation pattern are confirmed by the amino acid analysis and by NMR data.

In some bacterial cultures additional components with a succinic acid side (the hydrolysis product of succinamide) and with a methyl succinate side chain (1b and $\mathbf{1 c})$ could be found. The latter one may be an artifact (Demange et al., 1990).

\section{Ferribactins}

After total hydrolysis and TAP derivatization by GC/MS and GC analysis the presence of Ala, OHAsp, Dab, Glu, Lys, Orn and/or OHOrn and Tyr was established.

In its CA spectrum (Fig. 3) $[\mathrm{M}+\mathrm{H}]^{+}(\mathrm{m} / z$ 1109) loses up to $4 \mathrm{H}_{2} \mathrm{O}$ and also the Glu side chain (loss of $129 \mathrm{u}$, followed by that of 1 and $2 \mathrm{H}_{2} \mathrm{O}$ ). From the sequence specific ions (see Table II) $\mathrm{B}_{1}$ is of high abundance showing the loss of $\mathrm{H}_{2} \mathrm{O}$ and of $129 \mathrm{u}$. The same degradation is also observed for $\mathrm{A}_{1}$. $\mathrm{B}_{3}$ loses $\mathrm{H}_{2} \mathrm{O}$ and $\mathrm{HOOC}-\mathrm{CHO}$ (indicated by $\mathrm{McL})$ as described above. The ions characteristic for Lys $(\mathrm{m} / z, 129$ and 84; those for Orn and Dab disappear in the general noise) and for AcOHOrn $(\mathrm{m} / \mathrm{z}$ 86) can be seen in the quadrupole spectrum of $[\mathrm{M}+2 \mathrm{H}]^{2+}$ (cf. above).

From the ions characteristic for the $N$-terminal part of ferribactins only the cleavage product $\mathrm{HO}-\mathrm{C}_{6} \mathrm{H}_{4}-\mathrm{CH}_{2}-\mathrm{CH}=\mathrm{NH}_{2}{ }^{+}(m / z, 136)$ has been mentioned previously (Fuchs and Budzikiewicz, 2001a; Fuchs et al., 2001). In a recent publication (Budzikiewicz et al., 2006) it is shown that the ions $\mathrm{m} / z 154,182$ (present in the quadrupole spectra of both $[\mathrm{M}+\mathrm{H}]^{+}$and of $\left.[\mathrm{M}+2 \mathrm{H}]^{2+}\right), 400$ and 355

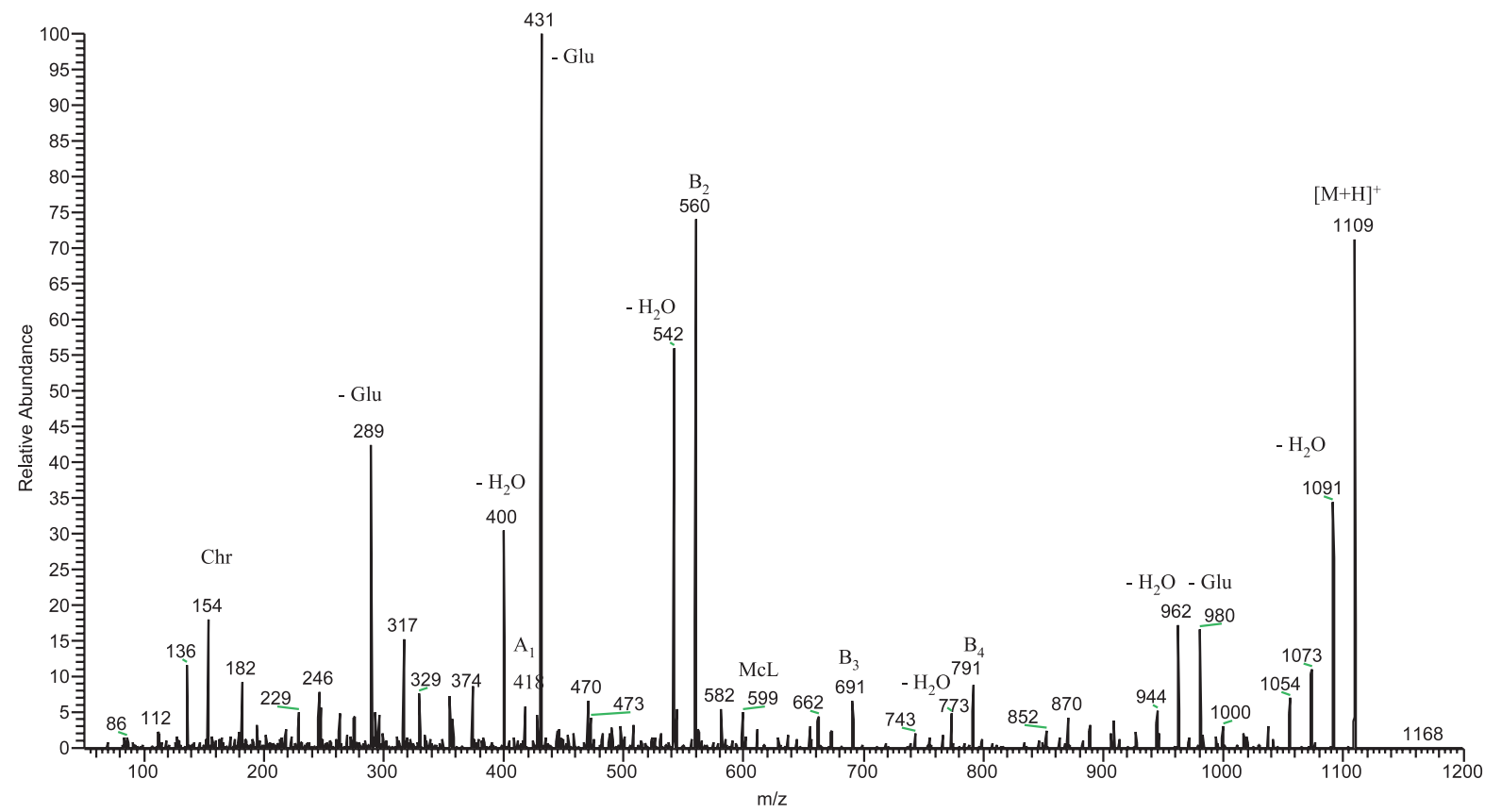

Fig. 3. Quadrupole ion CA mass spectrum of $[\mathrm{M}+\mathrm{H}]^{+}$of the ferribactin with a Glu side chain. Chr designates the fragments formed by further decomposition of $\mathrm{A}_{1}$; McL is the McLafferty fragment of $\mathrm{B}_{3}$ (see text). 


\begin{tabular}{|c|c|c|c|c|c|c|c|c|}
\hline \multirow[t]{2}{*}{$n$} & \multirow[t]{2}{*}{ Amino acid } & \multicolumn{2}{|c|}{ A } & \multicolumn{2}{|c|}{ B } & \multicolumn{2}{|c|}{$\mathrm{Y}^{\prime \prime}$} & \multirow[t]{2}{*}{$n$} \\
\hline & & Glu & Suca & Glu & Suca & Glu & Suca & \\
\hline 1 & Ala & 418 & 388 & & 416 & & & 6 \\
\hline 2 & Orn & & & 560 & 530 & & & 5 \\
\hline 3 & OHAsp & & & 691 & 661 & & & 4 \\
\hline 4 & Dab & & & 791 & 761 & 419 & 419 & 3 \\
\hline 5 & AcOHOrn & & & & & 319 & 319 & 2 \\
\hline 6 & Lys & & & & & 147 & 147 & 1 \\
\hline
\end{tabular}

Table II. Amino acid sequence characteristic fragment ions found in the MSCA spectra of $[\mathrm{M}+\mathrm{H}]^{+}$and/ or of $[\mathrm{M}+2 \mathrm{H}]^{2+}$ of ferribactin with Glu $N$-terminus (left columns) and with a succinamide $N$-terminus (right columns).

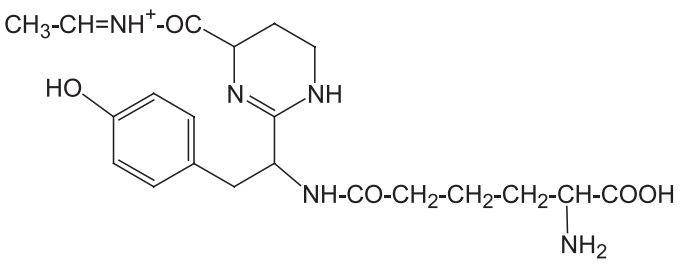

Fig. 4. Fragment ion $\mathrm{A}_{1}$ from the ferribactin $\mathbf{2 a}$ (2b has a $\mathrm{CO}-\mathrm{CH}_{2}-\mathrm{CH}_{2}-\mathrm{CONH}_{2}$ terminus).

(only from $[\mathrm{M}+2 \mathrm{H}]^{2+}$ ) are degradation products of the ion $\mathrm{A}_{1}$ (2a, Fig. 4) which still contain the tetrahydropyrimidine ring with the Ala residue.

A second compound exhibits a $[\mathrm{M}+\mathrm{H}]^{+}$ion at $\mathrm{m} / \mathrm{z} 1079$ in accordance with a succinamide instead of Glu $N$-terminus. Accordingly no losses of $129 \mathrm{u}$ are observed. $A_{1}$ and the $B$ ions and their further degradation products (see above) occur at masses $30 \mathrm{u}$ lower than those observed for the ferribactin with a Glu substituent (Table II). $A_{1}, B_{1}$ and $B_{2}$ show in addition loss of $\mathrm{NH}_{3}$ and $\mathrm{A}_{1}$ and $\mathrm{B}_{1}$ loss of the succinamide side chain $(-99 \mathrm{u})$. The ions 84 , 129 and 86 characteristic for Lys and AcOHOrn as well as $m / z, 136$ and 154 (see above) are present in the CA spectrum of $[\mathrm{M}+2 \mathrm{H}]^{2+}$.

\section{Discussion}

The type of siderophores (pyoverdin and ferribactin), the nature of the chromophore side chain, and the sequence of the amino acids in the peptide portion could be deduced from the CA spectra of their $[\mathrm{M}+\mathrm{H}]^{+}$and $[\mathrm{M}+2 \mathrm{H}]^{2+}$ ions. This is certainly not possible for every pyoverdin, but partial information at least can be obtained in most cases. Subsequent confirmation was obtained by identification of the amino acids after total hydrolysis (which was also necessary for determining their chiralities).
The siderophores of Pseudomonas sp. PS 6.10 are remarkable in several ways. A peptide chain with six amino acids is so far the lower limit observed for pyoverdins. Pyoverdins with a free $C$ terminal amino acid have been encountered, but in many cases it could be shown that they are the hydrolysis products of cyclodepsipeptidic precursors where the $C$-terminal carboxy group forms an ester bond with an in-chain hydroxy-amino acid (Ser or Thr). This safeguards the pyoverdin from an attack by enzymes able to degrade peptides starting from the $C$-terminus (Amann et al., 2000; Budzikiewicz, 2004). In the present case OHAsp is the only hydroxy-amino acid in the peptide chain, but it is one of the ligand sites for $\mathrm{Fe}^{3+}$ and thus can not be used for ester formation. Thus the $C$-terminal carboxy group must be free.

The identification of a feribactin with a succinamide $N$-terminus is remarkable also. With only one recent exception (see below) only Glu [and in one case derivatives of Glu (Uría Fernández et al., 2003)] was found which is considered to be the starting compound for the other pyoverdin side chains derived from the citric acid cycle. Succinamide as a side chain has been encountered at the beginning of the bacterial production of pyoverdins and in their immediate biogenetic precursors, the dihydropyoverdins (Budzikiewicz, 2004). In the meantime a second example was encountered. From the culture of a pyoverdin-negative transposon mutant of Pseudomonas fluorescens ATCC 17400 ferribactins with a Glu and with a succinamide $N$-terminus could be isolated (Budzikiewicz et al., 2006). It seems that a side chain modification of ferribactins can occur when a transformation into pyoverdin for some reason is hampered.

So far it was not quite obvious under which experimental circumstances precursors of the respective pyoverdins could be found in culture medium (Budzikiewicz, 2004; cf. also Uría Fernández et al., 
2003). This is the first case where different media lead to the production of variable amounts of pyoverdins and ferribactins, respectively.

Amann C., Taraz K., Budzikiewicz H., and Meyer J.-M. (2000), The siderophores of Pseudomonas fluorescens 18.1 and the importance of cyclopeptidic substructures for the recognition at the cell surface. Z. Naturforsch. 55c, 671-680.

Böckmann M., Taraz K., and Budzikiewicz H. (1997), Biogenesis of the pyoverdin chromophore. Z. Naturforsch. 52c, 319-324.

Budzikiewicz H. (2004), Siderophores of Pseudomonadaceae sensu stricto (fluorescent and non-fluorescent Pseudomonas spp.). Progr. Chem. Org. Nat. Prod. 87, $81-237$.

Budzikiewicz H., Schäfer M., Uría Fernández D., Matthijs S., and Cornelis P. (2006), Characterization of the chromophores of pyoverdins and related siderophores by electrospray tandem mass spectrometry. BioMetals (in press).

Dallakian P., Voss J., and Budzikiewicz H. (1999), Assignment of the absolute configuration of the amino acids of pyoverdins by GC/MS. Chirality 11, 381-386.

Demange P., Wendenbaum S., Linget C., Mertz C., Cung M. T., Dell A., and Abdallah M. A. (1990), Bacterial siderophores: structure and NMR assignment of pyoverdins $\mathrm{Pa}$, siderophores of Pseudomonas aeruginosa ATCC 15692. Biol. Metals 3, 55-170.

Fuchs R. and Budzikiewicz H. (2001a), Structural studies of pyoverdins by mass spectrometry. Curr. Org. Chem. 5, 265-288.

Fuchs R. and Budzikiewicz H. (2001b), Rearrangement reactions in the electrospray ionization mass spectra of pyoverdins. Int. J. Mass Spectrom. 210/211, 603612.

Fuchs R., Schäfer M., Geoffroy V., and Meyer J.-M. (2001), Siderotyping - a powerful tool for the characterization of pyoverdins. Curr. Top. Med. Chem. 1, $31-57$.

Georgias H., Taraz K., Budzikiewicz H., Geoffroy V., and Meyer J.-M. (1999), The structure of the pyover-

\section{Acknowledgement}

Patricia Munsch is acknowledged for the gift of the Pseudomonas sp. PS 6.10 strain, Christel Gruffaz and Annie Hoeft for technical assistance and GC analyses.

din from Pseudomonas fluorescens 1. 3. Structural and biological relationships of pyoverdins from different strains. Z. Naturforsch. 54c, 301-308.

Hohlneicher U., Hartmann R., Taraz K., and Budzikiewicz H. (1992), Struktur von Ferribactin aus Pseudomonas fluorescens ATCC 13525. Z. Naturforsch. 47b, $1633-1638$

Hohlneicher U., Schäfer M., Fuchs R., and Budzikiewicz H. (2001), Ferribactins as the biosynthetic precursors of the Pseudomonas siderophores pyoverdins. Z. Naturforsch. 56c, 308-310.

Hohnadel G. and Meyer J.-M. (1988), Specificity of pyoverdine-mediated iron uptake among fluorescent Pseudomonas strains. J. Bacteriol. 170, 4865-4873.

Meyer J.-M., Stintzi A., De Vos D., Cornelis P., Tappe R., Taraz K., and Budzikiewicz H. (1997), Use of siderophores to type pseudomonads: the three Pseudomonas aeruginosa pyoverdin systems. Microbiology 143, 35-43.

Meyer J.-M., Geoffroy V. A., Baysse C., Cornelis P., Barelmann I., Taraz K., and Budzikiewicz H. (2002), Siderophore-mediated iron uptake in fluorescent Pseudomonas: characterization of the pyoverdine-receptor binding site of three cross-reacting pyoverdines. Arch. Biochem. Biophys. 397, 179-183.

Munsch P., Geoffroy V., Alatossava T., and Meyer J.-M. (2000), Application of siderotyping for characterization of Pseudomonas tolaasii and 'Pseudomonas reactans' isolates associated with brown blotch disease of cultivated mushrooms. Appl. Environ. Microbiol. 66, 4834-4841.

Roepstorff P. and Fohlman J. (1984), Proposal of a common nomenclature for sequence ions in mass spectra of peptides. Biomed. Mass Spectrom. 11, 601.

Uría Fernández D., Fuchs R., Schäfer M., Budzikiewicz H., Meyer J.-M. (2003), The pyoverdin of Pseudomonas fluorescens G173, a novel structural type accompanied by unexpected natural derivatives of the corresponding ferribactin. Z. Naturforsch. 58c, 1-10. 